\title{
Some reflections before the Beginning of the Research Project on Modern Natural and Technological Challenges in Russia
}

\author{
Oleg N. Yanitsky \\ Ph.D., Professor, Chief Researcher, \\ Institute of sociology of the Federal Center of Theoretical and \\ Applied Sociology of the Russian Academy of Sciences.
}

\begin{abstract}
The article represents an attempt of qualitative modelling of the organization and the process of work on the research project titled the 'Volunteering in the Critical Situations as a Response to Natural and Technological Challenges in Russia' taking into account the main impediments and difficulties generated by the inside and outside forces. Such attempt seems necessary because we launch this project in very uncertain conditions such as the transition period of Russia toward the Forth scientific and technological revolution (hereafter the STR-4), the prevalence of mono-disciplinary mode of the research and teaching as well as by a very waste territory of Russia with highly dispersed habitat, especially in the North, Siberia and the Far East. Only the triad as the 'scientific knowledge-teaching-experience in situ' could offer to the rescuers and volunteers a necessary knowledge and social experience, and our project have to be organized in a right way. Therefore, I suggest to launch the work on the project 'from the end' i.e. from the anticipated results of it in the form of one or several hypotheses related to the final results of the project. Such mode of collaboration of the project's participants allows us to avoid a widespread mistake when the theoretical model of subject in question begins to contradict with the results of the following field-research.
\end{abstract}

Keywords: challenges, globalization, interdisciplinary approach, local population, research project, rescuers, the STR-4, theory, time, volunteering, Russia

\section{WHAT IS THE QUESTION?}

Usually, a research project proposal is written by one or two future leaders of it. But after the getting of its approval, and funding the number of its participants may be much larger, from five to ten researchers. If the majority of them are the students or the postgraduates, they become the only executors of the main aims of the research project. But if a research team is composed from the participants of more or less equal intellectual potentials and came from the various disciplines or research schools, their disagreements are unavoidable.

That is why I tried to foresee and analyze the main issues, disagreements and impediments before the launching the work on the project entitled the 'Volunteering in the Critical Situations as a Response to Natural and Technological Challenges in Russia' as one of its participants [1].

I predict the following types of limits and disagreements in a forthcoming research work: the outside limits and requirements imposed by global and national changes, and two forms of inside impediments. The former is a monodisciplinary character of professional capabilities of the project participants, and a multisided and complex character of the critical situations and their after-effects. The inside complexities is represented not by equal preparedness to deal with such complex multidisciplinary project, and by ill-organized process of conducting fieldresearch by individual participants. These complexities depend from a degree and forms of the state and activity of local people. 


\section{THE OUTSIDE AND INSIDE LIMITS AND REQUIREMENTS}

First, the sociologists are usually accustomed to deal with the stationary subjects which fluctuations (oscillations) can be measured in arithmetical terms like 'more or less', 'sooner or later', etc. But recently the world including Russia as its inseparable part is experiencing the qualitative transformations burdened by a speeding up of ongoing events. For such unstable and unpredictable world transformations a kind of systemic and transformative analysis should be developed. I stress the word 'transformative' because today any social agent has nonlinear and wave-like trajectory of its development. The very notion of the 'development' acquires a probabilistic character.

That is why the adherents of the 'modernism-postmodernism' paradigm prefer to deal with large historical epochs but not with the permanent transformative and multisided processes including numerous macro, middle and micro agents. It's not accidental that the most advanced sociologists are now armed with principle the 'weakness is the power.' The reverse side of the same coin is a time of natural and social transformations produced by the outer forces or inner and unseen changes within the body of a certain natural or social system. To my mind, not only Russian but all sociologists and naturalists across the world have to learn to think globally and locally in the same time. And besides, should learn the ABC of interdisciplinary research that allows them to analyze and construct the metabolic processes that have their own time and rhythms.

Second, the institutional structure of the RF is still relatively stable, but it's only on the first glance. The mater is the more we are moving top-down, from the Constitution of the RF to a law enforcement practice the more codes, instructions and restrictions we see. Besides, these institutions and practices are varied from a region to region and from town to town. The hacker's attacks acting immediately and directly on information systems of the objects and individuals are questioning this huge multilevel institutional structure at all. Up to now, the competition between stable social institutions and very mobile hackers win the latter. How to make hypotheses in such extremely uncertain and mobile conditions, that is the question!

Third and the most important, every accident has its own 'character', speed, and type and scale of harm. The time and resources for it immediate and long-term mitigation are different as well.

My conclusion is rather simple. In such uncertain conditions the process of coping with the CS after-effects is turned into a set of the immediate reactions to permanently coming challenges. The fundamental revision of institutional structure and law-making are usually postponed. But a permanently growing amount and scale of such challenges forced us to focus mainly on everyday challenges and their after-effects. Simultaneously global and national political leaders began to realize that global and national politics is quickly turning into the races with such challenges. In turn, it means that the gap between the 'fundamental' law-making and everyday politics including the coping with the CS after-effects is rapidly widening.

Meanwhile, a significance of volunteers' activity is growing because the state rescuers together with the bodies of social protection cannot foresee all modern forms of critical situations, like the hackers' attacks. Then, a commonly-accepted definition of the modern CS is still absent. Finally, I consider the volunteers' activity as very important sphere of civil responsibility and a mean of joint civil efforts in our individualized society. 


\section{THE LIMITS OF THE WORK OF THE RESEARCH TEAM}

There are two kinds of them: the outside and the inside ones and they are closely interdependent. The former are the pace of structural-functional transformations of the types of the CS and the kind of an impact which they are exert on natural, social and built environment.

The latter are divided in two subtypes. The first subtype is a time of adaptation of the research team members to the aims and tasks of the given research project. This adaptation of time is a function of a particular attitude on the researcher in relation to the project theme. As it often happens, the research consider his/her participation in the given research project as a source of gaining some additional income because their realm of the research interests is outside of the aims of a particular research project. My professional experience shows that usually only a half of the research team is really interested in the process and the outcomes of a given research project.

The second subtype indicates a degree of the preparedness of the particular researcher to share the aims, methods and theoretical background of the project. It's especially going on about an ability to be a real member of the united research team and to share an interdisciplinary and systemic approach to the coming research work.

\section{A REALM OF AN ACTIVITY OF THE STATE AND CIVIL VOLUNTEERS' ORGANIZATIONS, AND THEIR DEPENDENCE ON THE CS CHARACTER, A SPEED OF ITS COMING, LOCAL CONDITIONS, AND A TYPE OF HUMAN HABITAT}

The above conditions and characteristics are so diverse and permanently changing that the state rescue forces aren't capable to cope with thousands old and new challenges across a giant territory of our country with a variety of climatic and geographical conditions. More than that, many natural and technological disasters are now have a transnational character, and the biosphere plays the role of their transition across the world.

On the other hand, the state rescue forces aren't capable to save people and their belongings under conditions of a permanently mobile population. In such conditions well-trained and equipped local civic volunteers and their organizations are potentially capable to play the role of the rescuers in the small settlements and in the cases of nomadic people.

I think that under the processes of globalization of modern natural and technological challenges, construction of all-embracing information networks, and permanently growing spatial and social mobility of humans the functions of the state and civil rescuers will draw together.

Following the Barry Commoner's law that all connected with all, and the all in necessarily going somewhere, to construct the unified definition of a volunteers' movement, its immediate and ultimate goals, its spatial scale and structural-functional organization, etc. seems me impossible. It means that the old slogan of the Greens, 'To think globally, and to act locally' is still valid. In turn, it means that under current conditions the state and civil rescuers have to work hand in hand.

\section{THE AIMS AND TASKS OF THE RUSSIAN VOLUNTEERS UNDER TRANSITION TO THE FOURTH SCIENTIFIC AND TECHNOLOGICAL REVOLUTION (STR-4)}

First, the above transition as such generates numerous new critical situations, for example the reduction of labor market, stimulates the emergence of new waves of migration processes, and so on and so forth. In sum, a global geopolitical situation is becoming even more unstable. 
Second, the abovementioned and other transformations lead to the emergence of unknown forms of natural, technological and social metabolism. Thus, a necessity of close collaboration between the volunteers and scientific community is growing.

Third, the above metabolic transformations have to be studied not only in the higher schools but in secondary school and may be even earlier. Such transformations are points at an urgent necessity of making an interdisciplinary approach one of the basement principles of any rescue operations.

Fourth, under very unstable global conditions the population cannot be considered as the victims of the CS and passive receiver of aid of the rescuers. Recently the ordinary people are becoming active participants of the CS mitigation that requires a teaching of these people. It means that the principles and organizational forms of civil defense should be reconsidered in accordance with new conditions.

Fifth, to my mid, one of the first and foremost task is the defense of human privacy. The decay of traditional family and other local forms for the maintenance of this privacy doesn't mean that this primary eco-structure of human existence is now totally destroyed and disappeared (Yanitsky, 1982, 2012, Friedwald and Pohoryles, 2013). Recently the human privacy is simultaneously maintained and threatened by many other 'material' and virtual forms of communication, but it's still exists in many other forms.

Sixth, under conditions of transition towards the STR-4 the process of dying off the old social institutions and the emergence of a new one is going on. This situation 'in-between' aggravates an uncertainty of the above transition period.

Seventh, recently the hacking is an indispensable part of modern hybrid wars. The hybrid wars are one of the modern forms of current human relationships, be it material or virtual. The hybridization processes aren't equal to the metabolic once but sometimes they are closely interrelated.

Eighth, respectively the process of growing complexity of the structures and processes of natural, social and technological interactions leads to a growing scale of post-catastrophe rehabilitation of nature, humans and their built environment.

\section{A QUESTION OF COMPOSITION OF THE VOLUNTEERS' MOVEMENT BY ITS AGE, GENDER, ETHNO-CONFESSIONAL SPECIFIC, LEVEL OF EDUCATION, MIGRATION POTENTIAL, AND THE INDIVIDUALS' LIFE-PLANS}

The events of the last several years across the world clearly show that not only the teenagers and the young but the aged people are becoming the volunteers and civil activists. It doesn't surprising because a majority of them are voluntary or involuntary involved in the local-global processes that in one way or another are influencing the life of many people who are permanently or involuntary are becoming the migrants, shuttles, profiteers, and shift workers. From my viewpoint, based on a half-a-century experience of studies of nature protection and other social movements in the USSR/RF and abroad, the volunteer movement in many forms has been and recently is an important condition of civil enlightenment and a mean for surmounting of a consumerist attitude (both as the ideology and the way of life) to natural and social environment.

Speaking more generally, I consider current volunteers' movement as a king of a 'bridge' between a charity and philanthropic activity and real help here and now to the affected natural ecosystems and humans. 


\section{THE VOLUNTEERS' MOVEMENT BETWEEN THE 'SCYLLA AND CHARYBDIS'}

Of course, it's the image only. Nevertheless, due to the not equal relationships between the state and civil organizations (different funding, law and civil defense and many other circumstances) a problem of a potential field of civil activism in the CS, and of its limits is very acute and should be carefully discussed.

The state rescue forces are often criticized for their insufficient attention to organization of civil defense forces, their funding, education, etc., although this point is fixed in their Statute. On the other hand, the bodies of social protection of the population already began to expand as well. The third limiting force of the volunteers' activity expansion is so-called state volunteers. Therefore, I see the following spheres of the volunteers' activity.

The first one is a rapid transformation of the biosphere into the socio-bio-technosphere (hereafter the SBT-system) that has its own regularities of development. The regularities of functioning of this hybrid system and the risks and challenges that it produced should be a matter of the first hand attention of scientists, scholars together with volunteers and other civil activists. Under recent hybrid and very mobile conditions of all forms of life such very complex phenomena should be studied by interdisciplinary research teams in close cooperation with the volunteers.

Such collaboration will be useful for all sides. The scientist and scholars will gain necessary experience for testing their theories and hypotheses. As the Russian scientists, one of the authors of the Biosphere concept V. Vernadsky stated, the scientists has stated, 'the scientist has always to be in the midst of a man's and nature life.' The students, schoolchildren and the volunteers could join their knowledge and experience in situ. Finally, local population and municipal authorities will gain new knowledge from both sides. Only the triad as the 'scientific knowledge-teaching-experience in situ' could offer to the volunteers a necessary knowledge and social experience. Another world-known, the Noble laureate Russian academician Piotr Kapitza argued that in many cases the experimenter is more important than a theorist.

Therefore, I think that the participants of the above project should to concentrate on the issue of the volunteers' struggle against information challenges (for example, on the hackers' attacks), on the assistance to ordinary people to defense their private life as well as on the nature protection and its transformation into the SBT-systems of various scale.

Then, thousands of small towns and country settlements spread on the giant territory of Russia should become the subject-objects of volunteering. The subjects it's a socially-active part of residents of such settlements. The small settlements and the nomad camps deserve special attention because they use to live by hunting and fishing and have not been well-protected from criminals' and hackers' attacks.

\section{THE VOLUNTEERS' MATERIAL, INTELLECTUAL AND OTHER RESOURCES AND THEIR MOBILIZATION}

First of all the volunteers have to keep in mind that a time and its saving is a key resource for mobilization of human, material and other resources. Then, it's necessary to mobilize the intellectual resources of the universities and research institutes. After then, the residents' involvement in a separate collection of the wastes is going. The volunteers should work hand in hand with not politically-engaged experts. The last but not the least is the volunteers have to propagate the norms of a reasonable and sufficient consumption. 
Of course, there are many other places where the volunteers may to propagate the norms of a reasonable and sufficient consumption and recruit new members of the movement such as schools, universities, various public gathering, and so on. A business involvement into protection of natural and social environment is a tricky task because any businessman pursues the economic and political aims only. Nevertheless, there are some very reassuring examples. See, for example, the case of long-term struggle in defense of the lake Baikal.

\section{THE RELATIONSHIPS WITH SCIENTIFIC, EDUCATIONAL AND CONFESSIONAL ORGANIZATIONS}

I consider the any kind of the volunteering as an integrated form of their individual and public activity that combines various forms of professional and civil activity. In this point I fully agree with the viewpoint of A. Irwin and B. Wynne (1992). To my mind, the volunteer has to be very experienced person. His/her activity depends on the type and character of the CS and on a particular natural, social and built environment which this CS affects just now or it's going on about its immediate or long-term after-effects.

At best, the above relationships have to be friendly based on mutual understanding of the both sides. But in any case the volunteer should render a help to the affected people or natural ecosystems irrespectively of their personal values and confession. In this narrow case the volunteers are the cosmopolitan activists like the 'Doctors without the Borders.'

For the reason of rapidly going processes of hybridization of any kind of natural or human activity such experienced volunteers are highly valuable because they maintain and spread the interdisciplinary approach not only in the science and education but in an everyday life and social practice.

\section{THE LIMITS OF THE VOLUNTEERING IN THEIR STRUGGLE WITH NATURAL AND TECHNOLOGICAL CHALLENGES}

These limits are determined by the kind of the relationships of the volunteers with state rescue institutions (see Section 7). At the same time, an unlimited growth of amount and scale of the CS these factors will not only stimulate the growth of the state rescue institutions and of the bodies of social protection of the population and natural ecosystems but the involvement in this struggle local people arming him by necessary instruments and equipment (protective masks, clothes, etc.). The experience of massive floods and forest fires in Siberia and the Far East showed that the participation of the volunteers in the mitigation the after-effects of these disasters might be much more efficient, especially in the cases of small settlements and nomad camps. At the same time we shouldn't forget the experience of the civic defense system in the years of the Great patriotic war in the years of the 1941-45s.

\section{THE SOURCES AND METHODS OF COLLECTING OF EMPIRICAL DATA}

We are living now under conditions of permanent struggle between the hackers and constructors of defense means and instruments. Modern societies are moving toward a creation of an all-embracing system of permanent monitoring of all CS emerging on our planet but it's still unreal foe economic, geopolitical and other reasons. One of the possible ways out, I see in the creation of an entire network of the sources of insiders' information created by local volunteers' groups.

Then, a construction of a system generated the projective information seems to me one of acute tasks of our research project. The construction of such information system will allow us to be well prepared to the coming of various CS and to predict its possible consequences. 
Finally, as I noted earlier the scientist and scholars with the volunteers have to develop a set of defensive measures for the protection of the primary eco-structure from an outside invasion.

\section{THE ISSUE OF THE RELATIONSHIPS BETWEEN THE ABOVEMENTIONED PROJECT PARTICIPANTS}

The work on the previous research projects clearly showed that there is a certain gap between the theoretical model of a subject or object in question and its further empirical researches. In principle there is nothing to surprise because a hypothesis is not always turned into workable theory. But there are some common instruments which are reducing the emergence of such gaps. Among the most important of them I see the consent of the project participants with an initial hypothesis of a phenomenon or the process in question, an interdisciplinary approach, a permanent exchange of new information (or the ideas) between the project participants, and of course of a seminar of its participants and independent experts at least once in three months.

\section{CONCLUSION}

Since our project is at the very beginning, I offer to my colleagues to start from the construction of the hypotheses of each part of the project, and to attempt to conceptualize their processual and end relationships. In other words, I offer to begin from the 'end', that is from the expected results of our project. Surely, it will be the hypotheses but the hypotheses that should not contradict one another.

Therefore, I offer to spend the first year of our work to the maximally close contacts between both the professional participants of the project and their social and geopolitical milieu, i.e. with local people. In this case it will be easier to achieve the common and not contradictory results in the form of one or several hypotheses related to the final results of the project. I realize that a sharp change in global conditions or in the emergence of unknown CS (like biological or genetic arms), the aims and results of our project may be changed. But in any case it will be better if such unexpected CS or other transformations will be predicted and assessed by the joint efforts of our state and its civil society organizations. In any case, the triad such as the 'scientific knowledge-teaching-experience in situ', i.e. the reaction on the CS and forms of defense activity of local people, should be the guiding principles of our research work.

Funding: This article is funded by the Russian Scientific Fund, grant No 19-78-10052, the project 'Emergency volunteering as a reply to the natural and technological challenges in Russia'.

\section{Note}

1. I began to study risks, threats and the other CS in the late $1980 \mathrm{a}$ after the Chernobyl disaster and the work on this issue written by U. Beck (1992). In the 1998 I edited the book on the risks of the 'transition period' in Russia (Yanitsky, 1998, 2003). Later I continued to collaborate with U. Beck and other foreign and Russian sociologists who dealt with the same issues. In parallel, I tried to develop the concept of the primary eco-structure in its three time-space dimensions (Yanitsky, 1982, 2012).

\section{References}

Beck U. 1992. Risk Society. Toward a New Modernity. London: SAGE. 260 pp.

Friedwald M. and Pohoryles J. 2013. Technology and Privacy. Innovation: The European Journal of Social Science Research, 26 (1-2): 1-6.

Irwin A. and Wynne B., eds. 1996. Misunderstanding Science? The Public Reconstruction of Science and Technology. Cambridge: Cambridge University Press. 232 p. 
Yanitsky O. 1982. Towards an Eco-City: Problems of Integrating Knowledge with Practice. International Social Science Journal. Vol. XXXIV. No 3: 469-480.

Yanitsky 0. 2003. The Sociology of Risks. Moscow: LVS Publishing House. 192 c. (In Russ.).

Yanitsky 0. 2012. A Primary Eco-Structure: The Concept and its Testing. Social Analysis, Vo.2 No 2, pp. 7-24.

Yanitsky 0. 1998, ed. Russia: The Risks and Threats of a 'Transition Society.' Moscow: Institute of Sociology, Russian academy of sciences. 237 pp.

Yanitsky 0. 2019. A Transition Period: Aims of the Study, theory and Practice. Moscow: Russian Political Encyclopedia (In Russ.). 